\title{
Estresse e produtividade acadêmica
}

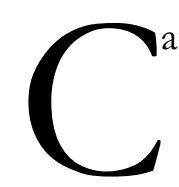

ausou grande repercussão na comunidade acadêmica nacional o artigo publicado recentemente pelo Prof. Leopoldo de Meis e cols. no Braz J Med Biol Res (36: 1135-1141, 2003) abordando a evolução temporal da produtividade científica brasileira e suas conseqüências sobre os pesquisadores. Na primeira parte do artigo (intitulado The growing competition in Brazilian science: rites of passage, stress and burnout), os autores utilizam métodos quantitativos de coleta de dados para demonstrar que, embora tenha havido um crescimento exponencial do número de publicações brasileiras indexadas, nos últimos anos, os recursos governamentais federais foram reduzidos significativamente (de mais de 1,6 bilhão de dólares em 1995 para perto de 400 milhões de dólares em 2001, Figura 1). Houve também um grande aumento na formação de pós-graduandos pelas universidades públicas brasileiras no período de 1990 a 2000, sem que o número de docentes dessas universidades tenha crescido e sem que tenha havido abertura de um número significativo de vagas de pesquisa na indústria e no governo. São ilustradas algumas situações em que um enorme contingente de candidatos ou projetos competiram por pouquíssimas bolsas ou auxílios para investigação (1154/10 no programa PROFIX do CNPq em 2001, por exemplo).

Na segunda parte do trabalho, através de entrevistas abertas e estruturadas, realizadas com pósgraduandos, pós-doutores e professores do Depar-
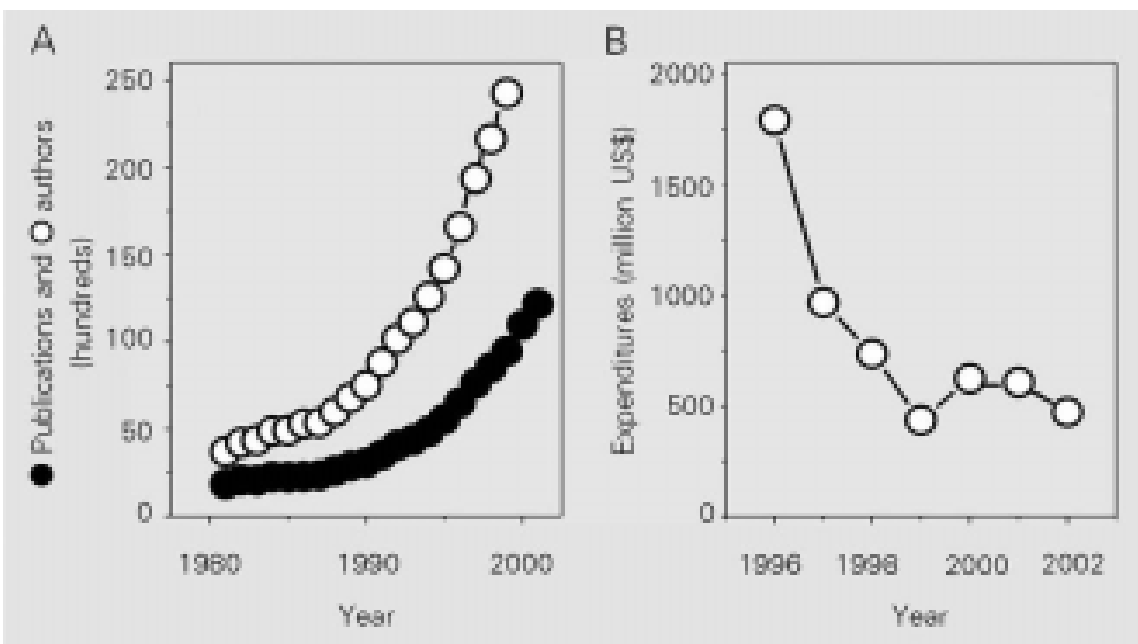

Figura 1: Publicações científicas, autores e gastos com ciência e tecnologia no Brasil.

Gráfico A. Número de autores brasileiros que aparecem em publicações indexadas pelo Instituto de Informação Científica (círculos abertos) e número de publicações indexadas originadas do Brasil (círculos fechados). Gráfico B. Gastos federais totais com ciência e tecnologia convertidos em dólares americanos (Fonte: SIAFI/STM, Elaboração: Consultoria de Orçamento/CD e PRODASEN). Reproduzido do Braz J Med Biol Res 36: 1135-1141, 2003, com permissão dos autores e dos editores. 
tamento de Bioquímica Médica da UFRJ e de outros departamentos, são reveladas as conseqüências psicossociais desta atividade altamente produtiva em face da escassez crescente de recursos: 1) grande envolvimento com o trabalho no laboratório, o qual englobava quase todo o tempo livre do pesquisador, levando a uma predominância de casamentos intra-departamentais (2/3 dos casais entrevistados); 2) ênfase absoluta na publicação de trabalhos científicos em revistas de alto fator de impacto e emergência de enormes estresse e frustração pessoal quando os artigos são rejeitados; 3) perpetuação dos "ritos de passagem" (transições ascendentes na carreira), em que o pesquisador tem que provar continuamente sua competência e está sempre arriscado a ser eliminado do sistema ou a ser desmoralizado dentro dele; e, finalmente 4) emergência de um estado de exaustão mental e emocional (burnout syndrome), causado por esperanças e expectativas frustradas, por um sentimento de controle inadequado sobre o próprio trabalho e de perda do sentido da vida. Segundo os autores, a probabilidade de desenvolvimento da síndrome aumenta com a intensidade e o prolongamento do estresse ocupacional, traduzido por trabalho excessivo e recursos inadequados para atingir as metas fixadas. A síndrome de burnout leva a uma perda progressiva do idealismo, deterioração do desempenho funcional e da saúde física e mental, causando aumento do consumo de álcool e de drogas ilícitas e arruinando as relações com familiares e amigos.

$\mathrm{Na}$ conclusão do artigo, os autores destacam que a radicalização da política de "publicar ou perecer" ("publish or perish"), no estágio ainda inicial do desenvolvimento científico brasileiro, está levando a um exagerado grau de competitividade entre os cientistas brasileiros, principalmente os mais jovens, propagando uma distorção cultural onde a cienciometria prevalece sobre o conhecimento e o sofrimento mental é diretamente proporcional à escassez de recursos. Neste cenário, uma proporção significante de cientistas poderão deixar a academia e os jovens talentos serão desencorajados a escolher a carreira científica, causando o declínio da ciência brasileira, que passaria do crescimento para a decadência, sem nunca ter atingido seu potencial pleno.

$\mathrm{O}$ artigo do Prof. de Meis poderia ser encarado, à primeira vista, como uma contribuição enviesada de um cientista frustrado e/ou incompetente, o que está longe da realidade, pois ele é um dos mais produtivos pesquisadores brasileiros, considerando os trabalhos indexados internacionalmente, além de ter servido nos mais altos comitês de formulação e avaliação da política científica nacional. A relevância dos seus achados para o nosso meio pode ser depreendida, de modo muito simples e direto, pela comoção causada em vários pesquisadores seniores do nosso Campus que assistiram a sua exposição sobre o tema no Hemocentro de Ribeirão Preto, algumas semanas após a publicação do artigo.

A pressão por publicações em revistas com altos índices de impacto, experimentada pela comunidade acadêmica brasileira de maneira crescente nos últimos anos, constitui apenas um dos muitos exemplos de desproporção gritante entre exigência de desempenho e disponibilidade de recursos. É revelador, neste sentido, constatar que apenas nove revistas biomédicas brasileiras, incluindo três de Veterinária e Zootecnia, têm o índice de impacto (IP) medido pelo Institute for Scientific Research e este índice, em todos os ca- 
sos, é inferior a 1,0. A pressão por publicações em revistas com maiores IF leva, inexoravelmente, os pesquisadores brasileiros a enviarem seus melhores trabalhos a revistas estrangeiras, onde enfrentam, além de feroz competição, formidável preconceito (vide "A qualidade da investigação científica no terceiro mundo e na FMRP-USP", Medicina-RP 28: 79-82, 1995). Apesar de muito comentada, a adoção de índices mais justos e fidedignos do que o fator de impacto para medir o valor dos vários tipos de trabalhos científicos, como, por exemplo, os dirigidos à prática clínica, parece ser uma tarefa quase inatingível.

Nas outras áreas da atividade acadêmica, a desproporção entre recursos disponíveis e exigências de desempenho são gritantes e se acentuam com a crise financeira das instituições de saúde, educação e de apoio à pesquisa do país. Na pósgraduação, por exemplo, o critério "tempo de titulação" impera de modo absoluto para a distribuição de bolsas, inviabilizando projetos de pesquisa mais complexos, por exemplo, ensaios clínicos que requerem longo tempo de observação. A maioria dos pós-graduandos não consegue bolsas, impelindo-os a outras atividades de sustento e aumentando o tempo de titulação, criando um ciclo vicioso. Quando são concedidas, as bolsas exigem dedicação exclusiva, mas têm um valor claramente insuficiente para a manutenção do pós-graduando e sua família (as federais pagam $\mathrm{R} \$ 855,00$ mensais para o mestrado e 1267,00 para o doutorado, já incluído o aumento recente de 18\%, o primeiro desde 1994)- ver: "Pós-graduação médica ameaçada", Medicina-RP 30: 1-4, 1997. A FAPESP, tradicional fornecedora de bolsas para a pós-graduação, com remuneração superior às federais, está restringindo fortemente seu atendimento e tende a encerrar o financiamento do Mestrado. Além disso, está limitando os estágios de pós-doutoramento no exterior, forma predominante de treinamento científico de recém-doutores, a ridículos 5 meses. Na graduação, turmas enormes de estudantes desmotivados (30-40/turma nos cursos intermediários) demandam aprendizado clínico qualificado em instalações hospitalares com espaço e pacientes inadequados, descarregando sua frustração sobre os docentes, nas avaliações de final de curso. Finalmente, todas essas atividades são significativamente prejudicadas quando o enxugamento de verbas para a saúde compromete o funcionamento dos hospitais universitários a ponto de colocar em risco a vida dos pacientes e o treinamento das várias categorias profissionais lá alocadas.

De alguns anos para cá, há uma tendência das Universidades mais sérias e das agências de financiamento de julgarem as atividades acadêmicas baseando-se em critérios internacionais, isto é, comparando as nossas instituições com as melhores do Primeiro Mundo e fixando metas de equiparação entre elas, processo pomposamente batizado de "internacionalização" da Universidade. Esses procedimentos se traduzem em recomendações de alto desempenho, como a publicação em revistas internacionais de alto índice de impacto e a inclusão de assessores estrangeiros em comitês de avaliação das nossas atividades. Pelo fato de não considerar as enormes diferenças entre a nossa realidade e a daqueles países, incluindo-se aí o desnível abissal de salários, essas metas de internacionalização geram pressões adicionais na comunidade científica. Geram também grande frustração quando as recomendações dos comitês de avaliação, visando a melhoria das atividades, não são consideradas, o que quase sempre acontece. 
Diante deste quadro, não é de se estranhar que muitos de nossos colegas, para se protegerem da síndrome de burnout, tenham se recusado a assumir grandes riscos na carreira acadêmica (orientar muitos pós-graduandos, coordenar grandes projetos de pesquisa, organizar e coordenar serviços clínicos complexos, publicar em revistas de circulação internacional, etc), mantendo-se, burocraticamente, nas atividades rotineiras mais simples. Os outros, que assumem maiores riscos com planos mais ambiciosos, têm que analisar detidamente a trajetória dos seus projetos para não serem engolidos pela síndrome e confundirem os percalços contingenciais com fracassos pessoais.

O lamentável atraso na publicação da revista Medicina-RP, motivado também por escassez de recursos, explica o descompasso ilógico entre as datas do artigo (set/2003) e palestra (out/2003) do Prof. de Meis e a data de capa deste número (out/dez 2002). As dificuldades financeiras da Revista, comuns entre as publicações científicas brasileiras, são decorrentes da restrição de verbas para a produção e divulgação da ciência no Brasil. Constitui outro exemplo de situação estressante que obriga os editores, além de zelar pela qualidade do conteúdo da revista, a preocupar-se com o suporte material para a continuidade da publicação.

\footnotetext{
Prof. Dr. Júlio C. Voltarelli

Professor Associado do Departamento de Clínica Médica da FMRP-USP e Membro da Comissão de Publicação da Revista "Medicina-RP”
} 